Dokuz Eylül Üniversitesi-Mühendislik Fakültesi Fen ve Mühendislik Dergisi Cilt 20, Sayı 60, Eylül, 2018
Dokuz Eylul University-Faculty of Engineering Journal of Science and Engineering Volume 20, Issue 60, September, 2018

DOI: $10.21205 /$ deufmd.2018206075

\title{
Eşdeğer Kütle-Yay-Sönüm Elemanı Kullanılan Ankastre Kompozit Bir Kirişin Titreşim Analizi
}

\author{
Şahin YAVUZ ${ }^{* 1}$, Mehmet UYAR ${ }^{2}$, Levent MALGACA ${ }^{3}$, Hira KARAGÜLLE ${ }^{4}$ \\ Dokuz Eylül Üniversitesi, Mühendislik Fakültesi, Makine Mühendisliği Bölümü, 35397, İZMİR \\ 1(ORCID: 0000-0001-9007-772X) \\ 3 (ORCID: 0000-0003-2019-8758) \\ ${ }^{4}$ (ORCID: 0000-0001-5546-7538) \\ Bayburt Üniversitesi, Mühendislik Fakültesi, Makine Mühendisliği Bölümü, 69000, Bayburt \\ ${ }^{2}$ (ORCID: 0000-0003-3511-7682)
}

(Alınış / Received: 10.01.2018, Kabul / Accepted: 04.06.2018, Online Yayınlanma / Published Online: 15.09.2018

Anahtar Kelimeler Özet: Kompozit malzemeler hafif ve dayanıklı oldukları için Kompozit kiriș, Titreşim analizi, Eşdeğer sistem, manipülatör olarak endüstriyel yapılarda yaygın olarak kullanılmaktadır. Bu çalışmada, [0/90] oryantasyona sahip ankastre kompozit bir kirişin titreşim analizi çalışılmıştır. Yapının ucuna kütle eklenmiştir. Başlangıç koşulu olarak deplasman uç noktaya uygulanmış ve deneysel sistemin serbest titreşimi elde edilmiştir. Eksponansiyel sönüm bulunmuştur. Titreşim sinyalinin Hızlı Fourier dönüşümü kullanılarak doğal frekanslar hesaplanmıștır. Sistem ANSYS programında analiz edilmiș ve simülasyon sonuçları elde edilmiştir. Sönüm katsayısı, deneyden elde edilen eksponansiyel sönümden yararlanılarak hesaplanmiştır. Deneysel ya da simülasyondan elde edilen statik çökme, doğal frekans ve eksponansiyel sönüm kullanılarak sistemin eşdeğer kütle-yay-sönüm elemanı oluşturulmuştur. Eşdeğer kütle-yay-sönüm elemanı sonuçları Laplace dönüşüm metodu ile elde edilmiştir. Deneysel, simülasyon ve analitik sonuçlar uç noktanın farklı başlangıç yer değiştirme değerleri için karşılaştırılmıştır. Sonuçların uyumluluğu gözlemlenmiştir.

\section{Vibration Analysis of a Cantilever Composite Beam by Equivalent Mass- Spring-Damper Systems}

\begin{tabular}{l}
\hline Keywords \\
Composite beam, \\
Vibration \\
analysis, \\
Equivalent \\
system, \\
ANSYS
\end{tabular}

\begin{abstract}
Composite materials are widely used in industrial structures such as manipulators because they are lightweight and durable. In this work, the vibration analysis of a cantilever composite beam with [0/90] lay-up was studied. An end point mass was added to the structure. An initial displacement was applied to the end point and the free vibration was analyzed experimentally first. Exponential decay was found. Natural frequencies were


determined by taking the Fast Fourier Transform of the vibration signal. The system was analyzed in ANSYS and simulation results were obtained. The damping coefficient was determined by trial using the experimental exponential decay. An equivalent massspring-damper model (MSD) was established using static deflection, natural frequency and exponential decay obtained experimentally or by simulation. MSD-analytical results were obtained by the Laplace transform method. The experimental, simulation, and analytical results were compared for different end point initial displacement values. It was observed that the results are in good agreement.

*Sorumlu yazar: sahin.yavuz@deu.edu.tr

\section{Giriş}

Kompozit malzemeler hafif ve dayanıklı olmalarından dolayı son zamanlarda çelik ve alüminyum gibi malzemelerin yerini almıștır. Hafif ve dayanıklı olmalarıyla birlikte esnekliği de büyük ölçüde arttırmaktadır. $\mathrm{Bu}$ yüzden, esnek sistemlerin titreşim analizi önemli araștırma konularından biri haline gelmiştir.

Kompozit kirişlerin modellenmesi ve titreşim analizi farklı kiriş teorileri kullanılarak gerçekleştirmişlerdir [1-3]. Eksenel yüklenmiş genel katmanlı kompozit kirişler için geliştirilen serbest titreşim ve burkulma analizi konularında çalışmışlardır [4,5]. Araştırmacılar çeşitli sınır koşulları için kompozit kirişlerin doğal frekansları, titreşim biçimleri ve burkulma yüklerini hesaplamak için dinamik rijitlik yöntemi kullanmışlardır. Polinomlar ve Rayleigh-Ritz yöntemine dayanan boyutsal azaltma yöntemini geliştirmişlerdir. Boyutsal azalma yönteminde, kesit özelliklerini belirlemek için polinom serilerini kullanmışlardır $[6,7]$.

Hızlı Fourier Dönüşümü (FFT) titreşim analizi, gemi yapıları, kompozit malzemeler ve dinamik özellikler gibi çeşitli uygulamalarda kullanılır [8-10]. Statik durumlar altında hata tespitleri için geleneksek FFT yaklaşımını kullanmışlardır [11], ayrıca dönel makinalarda hata tespiti için ise Wavelet
Pocket Dönüşümünü kullanmışlardır [12]. Haosheng vd. [13] makina titreşimlerinin yüzey topografisine etkisini belirlemek için FFT analizi ve dalgacık yeniden yapılandirma (Wavelet reconstruction) yöntemine çalışmasında yer vermiş̧tir. Kabel vd. [14] kompozit Voksellerin Moulinec-Suquet FFT temelli homojenizasyon yöntemine uygulanmasının etkilerini göstermiştir. Görüldüğü gibi, FFT yöntemi mühendislikte birçok alanda kullanılmaktadır.

Farklı dinamik koşullar altında sönüm oranı, artık titreşimler ve doğal frekanslar gibi sistem davranışlarını elde etmek, mekanik sistemlerde titreşim analizinin amaçlarındandır.

Mekanik Titreşimler teorisinde ve yapılan çalışmalarda metal yapılardan oluşan ankastre bir kirişin analitik modelinin elde edilmesi bilinen bir konudur[15]. Ancak bu çalışmada metal olmayan bir yapı olarak ankastre bir kompozit kiriş ele alınarak literatüre özgün bir katkı yapılmıştır. Bu çalışmada [0/90] katmanlı kompozit bir kirişin deneysel titreșim analizi yapılmıştır. Deneysel titreşim analizine dayanarak tek serbestlik dereceli analitik sistemin matematik modeli kurulmuştur. Deneyle elde edilen titreșim cevabından sönüm oranı ve doğal frekans gibi sistem parametreleri elde edilmiştir. Analitik çözümde kullanılması için kütle, yay ve sönüm katsayıları 
bulunmuştur. Kompozit kirişin ve analitik modelin doğal frekans ve serbest titreşim zaman cevapları karşılaştırmalı olarak sunulmuştur.

\section{Deneysel Sistem}

Bu çalışmada kullanılan deneysel sistem Şekil-1 de gösterilmiştir.

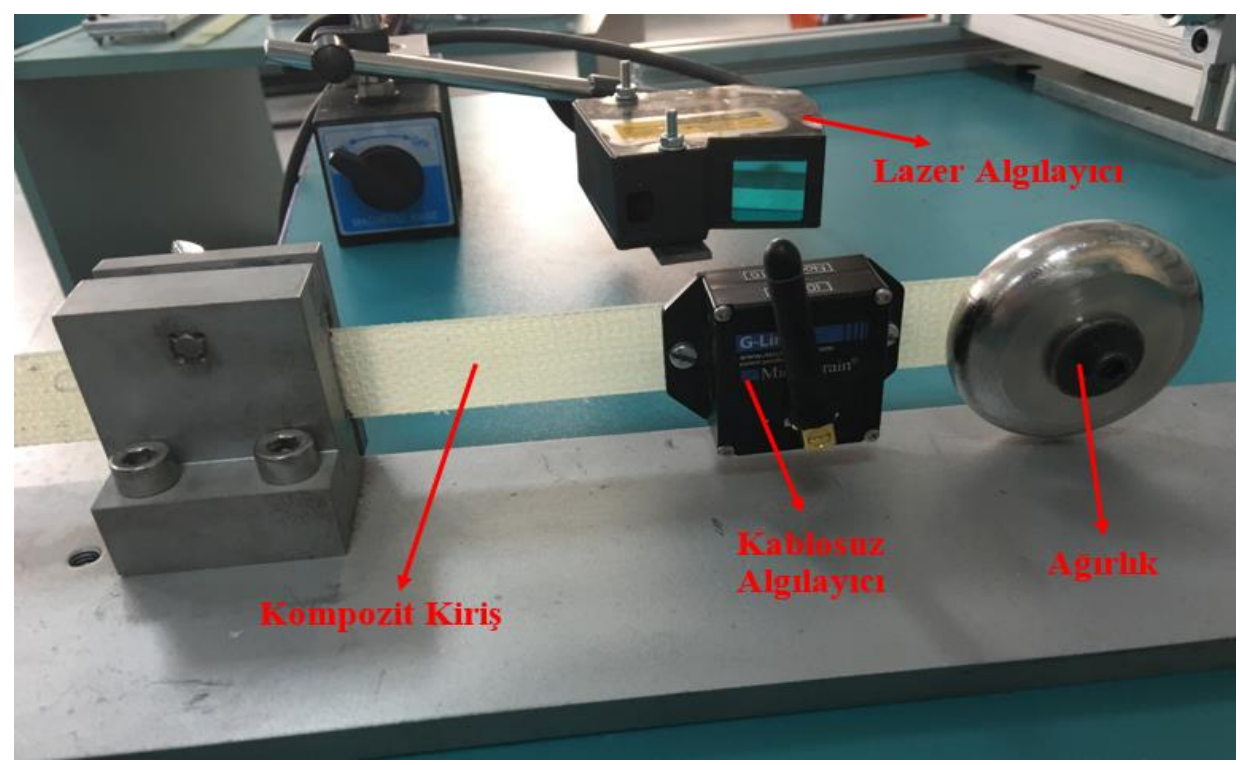

Şekil 1. Deneysel sistem

Deneysel sistem kompozit kiriş, kablosuz algılayıcı, kablosuz veri toplama sistemi, lazer algilayıc1 ve bilgisayardan oluşmaktadır. Kablosuz algılayıcı deney sistemi için kompozit kirişe cıvatalarla bağlanmıștır. Benzetim çalışmasında ise kompozit kirişin dinamik davranışını etkilediği için topaklanmış kütle olarak dikkate alınmıştır. Lazer algılayıcı sadece kompozit kirişin yer değiştirmesinin başlangıç değerini belirlemek için kullanılmıştır.

[0/90] katmanlı kompozit kiriş woven cam fiber/epoksi kompozit plakadan üretilmiştir. Woven cam fiberin alan yoğunluğu $500 \mathrm{~g} / \mathrm{m}^{2}$ dir. Matris malzemesi olarak Araldite LY 564 ve Aradur 3487 BD den oluşan epoksi kullanılmıştır. Kürleme işlemi 80 derece sıcaklık altında 8 saat boyunca gerçekleștirilmiştir.

MicroStrain WDA sistemi [16] kompozit kirişin belirlenen noktasındaki ivme değerlerini ölçmek için kullanılmıştır. WDA sistemi üç bileşenden oluşmaktadır; kablosuz algilayıcı, verileri alan ve bilgisayara aktaran USB istasyonu ve verileri bilgisayara kaydeden yazılımdır. Kablosuz algılayıcı üç yönlü ivme değerini ölçmeye olanak sağlar. Yazılımda kablosuz algılayıcıdan gelen veri için örnekleme frekansı $617 \mathrm{~Hz}$ ve alçak geçiş filtresi $5 \mathrm{~Hz}$ olarak ayarlanmıștır.

Kompozit kirişin serbest titreşim cevabını ölçmek için deneyde $3 \mathrm{~mm}$ ve $6 \mathrm{~mm}$ olarak iki farklı başlangıç yer değiştirmesi verilmiștir. Deneysel olarak elde edilen serbest titreşim cevapları Şekil-5'te gösterilmiştir.

\section{Sonlu elemanlar yöntemiyle titreşim analizi}

Kirişin sonlu eleman modeli ANSYS/APDL programında kabuk elemanlar kullanılarak oluşturulmuştur. Kompozit kirişi katmanlarıyla birlikte ifade 
edebilmek için SHELL181 elemanı kullanılmıştır. Sonlu eleman modeli 4727 eleman ve 4940 düğüm noktasından meydana gelmektedir. Deneysel sistemde bulunan kablosuz algılayıcı ve kirişin uç noktasına bağlanan ağırlık Şekil-2'de gösterilen benzetim çalışmasında topaklanmış kütle olarak dikkate alınmıştır. Kablosuz algılayıcının ağırlığı 54 gr ve kirişin uç noktasından olan mesafesi $80 \mathrm{~mm}$ olarak tanımlanmıștır. Uç noktaya bağlanan ağırlık ise 394 gr ve uç noktadan olan mesafesi $12 \mathrm{~mm}$ olarak tanımlanmıştır.

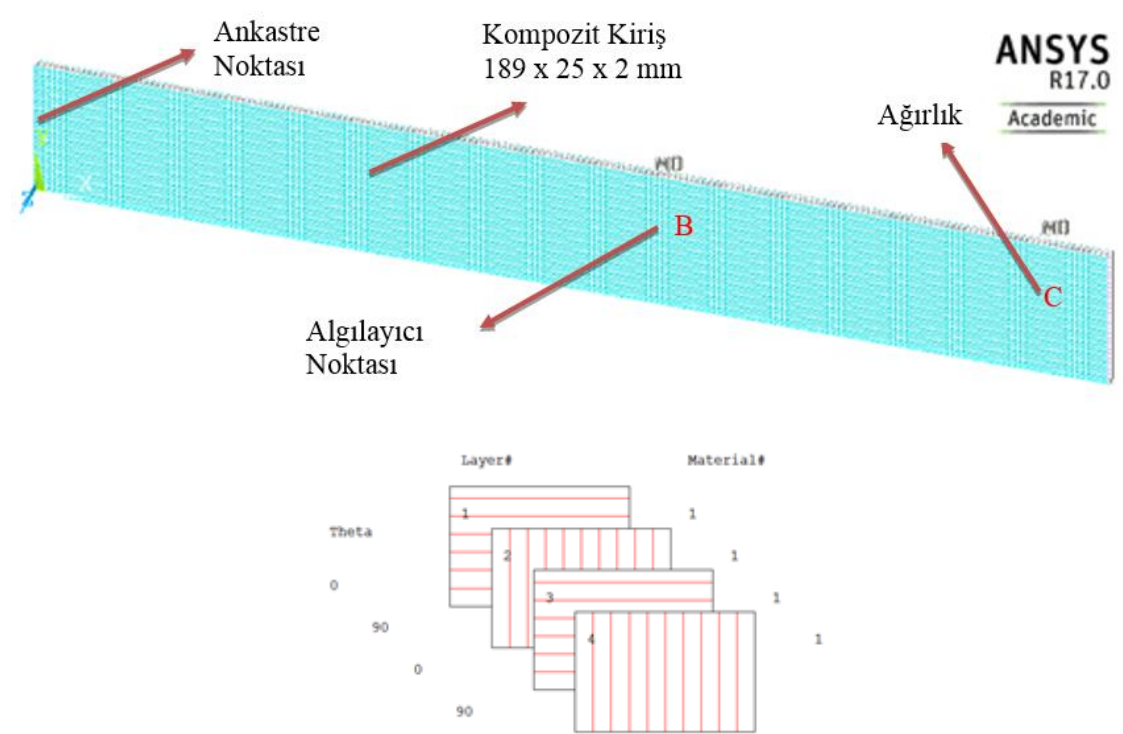

Şekil 2. Kompozit kirişin sonlu eleman modeli

Dört katmandan oluşan kompozit kirişin her bir katmanı için oryantasyonları ve malzeme özellikleri tanımlanmıştır.
Kompozit kirişin malzeme ve geometrik özellikleri Tablo-1'de verilmektedir.

Tablo 1. Kompozit kirişin özellikleri

\begin{tabular}{llll}
\hline Tanım & Değer & Tanım & Değer \\
\hline $\begin{array}{llll}\text { Fiber Yönündeki } \\
\text { Elastisite Modülü }\end{array}$ & $\mathrm{E}_{1}=23800 \mathrm{MPa}$ & Kiriş Uzunluğu & $\mathrm{L}=189 \mathrm{~mm}$ \\
$\begin{array}{l}\text { Fibere Dik Yöndeki } \\
\text { Elastisite Modülü }\end{array}$ & $\mathrm{E}_{2}=11200 \mathrm{MPa}$ & Kesit Uzunlukları & $\mathrm{b}=25 \mathrm{~mm}, \mathrm{~h}=2$ \\
Poison Oranı & $v_{12}=0.16$ & Kesit Alanı & $\mathrm{A}=50 \mathrm{~mm}^{2}$ \\
Kayma Modülü & $\mathrm{G}_{1}=3400 \mathrm{MPa}$ & Kesit Atalet Momenti & $\mathrm{I}=16.67 \mathrm{~mm}^{4}$ \\
& $\mathrm{G}_{2}=3250 \mathrm{MPa}$ & & \\
& $\rho=1.78 \mathrm{~g} / \mathrm{cm}^{3}$ & Kablosuz Algılayıcı Ağırlığı & $\mathrm{m}_{\mathrm{p}}=54 \mathrm{~g}$ \\
Yoğunluk & & Uç Nokta Ağırlığı & $\mathrm{m}_{\mathrm{u}}=394 \mathrm{~g}$ \\
\hline
\end{tabular}

Kompozit kirişin modellenmesinden analiz gerçekleștirilmiştir. Kompozit sonra doğal frekansları bulmak için modal kirişin ilk üç titreşim biçimlerine karşılık 
gelen doğal frekansları Tablo-2'de listelenmiştir.

Tablo 2. Kompozit kirișin doğal frekansları

\begin{tabular}{lll}
\hline \multirow{2}{*}{$\begin{array}{l}\text { Doğal } \\
\text { Frekans }\end{array}$} & \multicolumn{2}{c}{$[0 / 90]$} \\
\cline { 2 - 3 } & $\begin{array}{l}\text { Benzetim } \\
(\mathrm{Hz})\end{array}$ & $\begin{array}{l}\text { Deneysel } \\
(\mathrm{Hz})\end{array}$ \\
\hline 1. & 3.085 & 3.088 \\
2. & 38.38 & 37.28 \\
3. & 47.7 & 46.24 \\
\hline
\end{tabular}

Deneysel olarak alınan verinin frekans spektrumu Şeil-3'te gösterilmiştir.

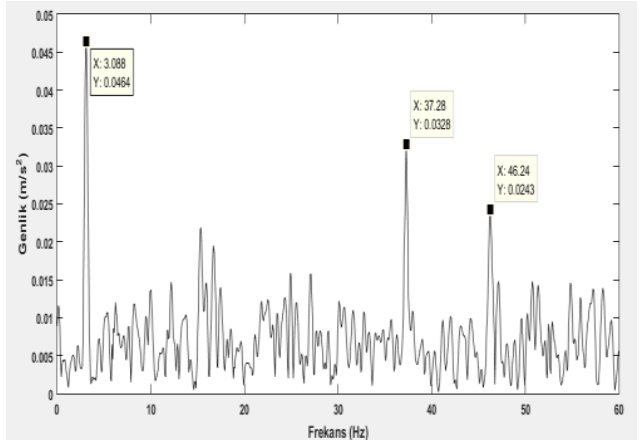

Şekil 3. Deneysel zaman sinyalinden FFT (Hızlı Fourier Dönüşümü) ile elde edilen frekans spektrumu

Titreşim analizi için başlangıç değer koşulu uygulanmış ve dinamik analiz gerçekleștirilmiştir. Benzetim ve deneysel analiz sonuçları karşılaştırılmalı olarak Şekil-4'te gösterilmiştir.

Benzetim çalışmasında zaman adımı sistemin birinci doğal frekansı dikkate alınarak 0.001 s seçilmiştir. Kompozit kirișin sönümünü dikkate almak için Rayleigh sönüm kullanılmıştır. $\mathrm{Bu}$ çalışmada Rayleigh sönüm katsayısı $(\beta)$ 0.0004 olarak belirlenmiștir.

\section{Analitik titreșim analizi}

Deneysel sistemden elde edilen kütle (m), yay (k) ve sönüm sabiti (c) değerlerini tanımlamak için Şekil-4'te gösterilen tek serbestlik dereceli eșdeğer bir sistem kurulur. Burada $\mathrm{x}(\mathrm{t})$ kütlenin yer değiștirmesinin zamana bağlı fonksiyonunu ifade etmektedir.

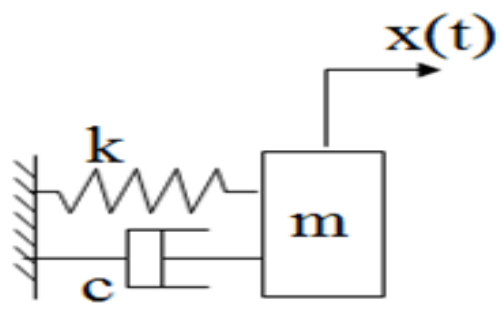

Şekil 4. Tek serbestlik dereceli eşdeğer sistem

Sistemin kütle, yay ve sönüm sabitlerini bulabilmek için deneysel sistemin dinamik özelliklerinden yararlanılır. Kirișin kablosuz algılayıcı ve uç noktasındaki ağırlıkla birlikte toplam ağırlığı 0.47 kg'dır. Sistemin yay sabitini bulabilmek için Denklem 1'de gösterilen birinci doğal frekans değeri dikkate alınmıştır. Sistemin birinci doğal frekansı Tablo 2'de $3.088 \mathrm{~Hz}$ olarak verilmektedir. Böylece yay sabiti aşağıda verilen denklemlerle hesaplanabilir.

$$
\begin{aligned}
& f_{0}=\frac{\sqrt{\frac{k}{m}}}{2 \pi} \\
& k=4 f_{0}{ }^{2} \pi^{2} m
\end{aligned}
$$

Denklem 2'de bilinen değerler yerine konulduğunda yay sabiti $176.94 \mathrm{~N} / \mathrm{m}$ olarak hesaplanır. Sönüm sabiti Şekil 4 de gösterilen deneysel titreşim cevabından logaritmik azalma fonksiyonu kullanılarak hesaplanabilir. Denklem 4-5 ve 6 da verilen denklemler kullanılarak logaritmik azalma fonksiyonu ile sönüm katsayısı hesaplanır. Logaritmik azalma fonksiyonu sönümlü titreşimin genliklerinin azalma oranını temsil eder.

$$
\frac{x_{1}}{x_{2}}=\frac{X_{0} e^{-\zeta w_{n} t_{1}} \cos \left(w_{d} t_{1}-\phi_{0}\right)}{X_{0} e^{-\zeta w_{n} t_{2}} \cos \left(w_{d} t_{2}-\phi_{0}\right)}
$$

$t_{1}$ ve $t_{2}$ birbirini takip eden iki genliğin zamanını ifade etsin. Buradan, $t_{2}=t_{1}+\tau_{d}$ yazılabilir. Burada $\tau_{\mathrm{d}}$ sönümlü titreşimin 
periyodu olur ( $\left.\tau_{\mathrm{d}}=2 \pi / \omega_{\mathrm{d}}\right)$. Böylece, denklem aşağıdaki gibi düzenlenebilir.

$$
\frac{x_{1}}{x_{2}}=\frac{X_{0} e^{-\zeta w_{n} t_{1}}}{X_{0} e^{-\zeta w_{n}\left(t_{1}+\tau_{d}\right)}}=e^{\zeta w_{n} \tau_{d}}
$$

Denklem 4'te eşitliğin iki tarafının logaritması alınırsa logaritmik azalma $\delta$ aşağıdaki gibi elde edilir.

$$
\begin{aligned}
& \delta=\ln \frac{x_{1}}{x_{2}}=\zeta \omega_{n} \tau_{d} \\
& =\zeta \omega_{n} \frac{2 \pi}{\omega_{n} \sqrt{1-\zeta^{2}}}=\frac{2 \pi \zeta}{\sqrt{1-\zeta^{2}}} \\
& =\frac{2 \pi}{\omega_{d}} \frac{c}{2 m}
\end{aligned}
$$

Denklem düzenlenirse sönüm katsayısı Denklem 6'daki gibi elde edilir.

$$
c=2 \zeta \sqrt{\mathrm{km}}
$$

Denklem 5 kullanılarak sönüm oranı $\zeta=0.055$ ve Denklem 6'dan yararlanılarak sönüm katsayısı c=0.1004 Ns/m olarak hesaplanır. Tek serbestlik dereceli sistemin matematik modeli Denklem 7 de verilmiștir.

$$
m \ddot{x}(t)+c \dot{x}(t)+k x(t)=0
$$

Doğrusal diferansiyel denklemlerin çözümü için Laplace dönüşümü kullanılabilir. Yer değiștirmenin zamana bağlı fonksiyonunun Laplace dönüşümleri Denklem 8-10 arasında verilmektedir.

$$
\begin{aligned}
& \mathcal{L}(x)=X(s) \\
& \mathcal{L}(\dot{x})=s X(s)-x_{0} \\
& \mathcal{L}(\ddot{x})=s^{2} X(s)-s x_{0}-\dot{x}_{0}
\end{aligned}
$$

Denklem 8-9 ve 10, Denklem 7 de yerine konulursa başlangıç değerleri altında sistemin transfer fonksiyonu Denklem 11 de görüldüğü gibi düzenlenebilir.

$$
X(s)=\frac{(m s+c) x_{0}}{m s^{2}+c s+k}
$$

Deneysel ve benzetim çalışmalarında elde edilen titreşim cevapları ivme cinsinden verildiğinden, $\mathrm{X}(\mathrm{s})$ in ikinci türevinin transfer fonksiyonunu ifade edebilmek için Denklem 11, s² ile çarpılır. Ardından, $\mathrm{X}(\mathrm{s})$ basit kesirlere ayrlarak zamana bağlı ivme fonksiyonu $x(t)$ ters Laplace dönüşümüyle elde edilir. Başlangıç yer değiştirmesi $\mathrm{x}_{0}=3 \quad \mathrm{~mm}$ için, $\mathrm{x}(\mathrm{t})$ fonksiyonunun ikinci türevi olan ivme fonksiyonu Denklem 12'deki gibi yazılabilir.

$$
\ddot{x}(t)=1.129 e^{-0.1067 t} \cos (19.402 t+3.136)
$$

Deneysel, benzetim ve analitik titreşim cevapları karşılaştırmalı olarak Şekil 5'te gösterilmiștir. Şekil 5'den de görüldüğü gibi, sonuçlar birbiriyle oldukça uyumludur.

$\mathrm{Bu}$ çalışmada oryanstasyonun etkisi incelenmemiştir. Ancak, kompozit yapılarda oryantasyonun doğal frekans ve sönüm oranı üzerinde etkisi araştırma konularındandır [17]. Yazarlar önceki çalışmalarında $[0]_{2 \mathrm{~s}}$, $[0 / 90]_{s},[45 /-45]_{s},[90]_{2 s}$ oryantasyona sahip simetrik katmanlı kompozit yapıların titreşim cevaplarını incelemişler, en yüksek sönüm oranının $[90]_{2 s}$ 'te olduğunu, en yüksek ilk doğal frekansın $[0]_{2 s}$ 'te olduğunu saptamışlardır. Eğilme yünündeki frekanslarda $0^{\circ}$ oryantasyonunun daha etkili olduğu, $90^{\circ}$ ise eğilme frekanslarını düşürdüğü sonucuna varılmıştır. 


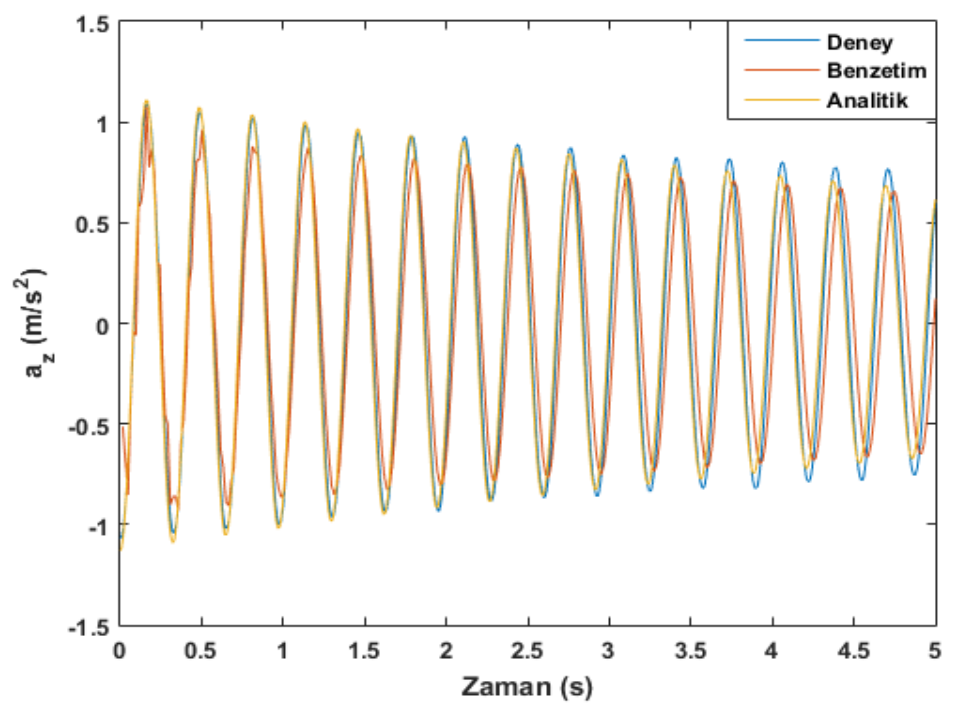

(a)

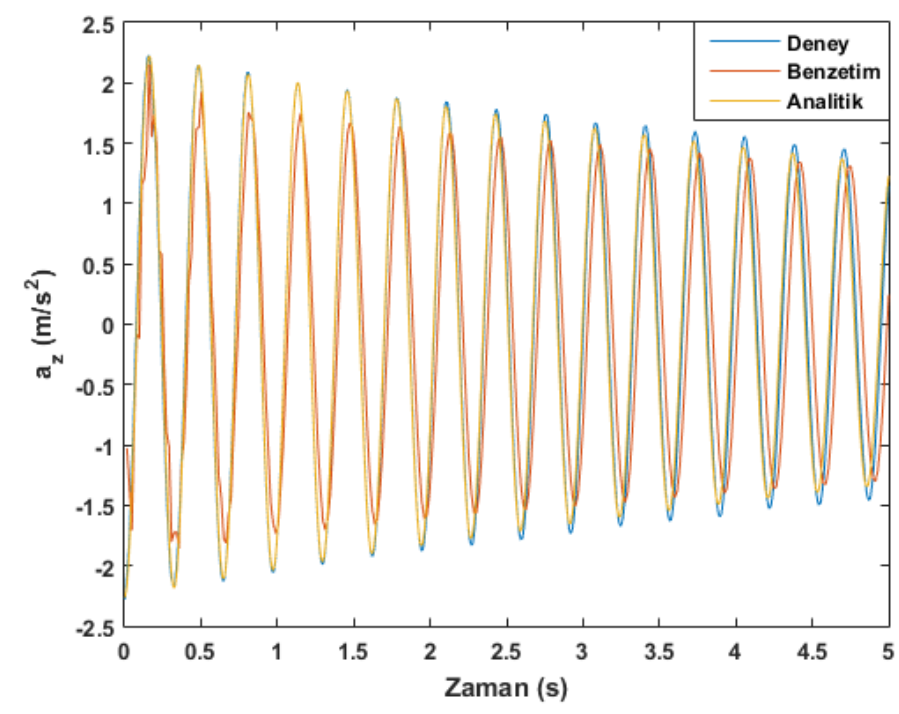

(b)

Şekil 5. Başlangıç yer değiştirme değerleri altında titreşim cevapları (a) 3 mm ve (b)

$6 \mathrm{~mm}$

\section{Sonuç}

Bu çalışmada [0/90] katmanlı kompozit bir kirişin serbest titreşim analizi için deneysel bir sistem tanıtılmıştır. Kompozit kirişin serbest titreşim cevabı deneysel olarak elde edilmiştir. Sistemin doğal frekans ve sönüm oranı deneysel titreșim cevabından hesaplanmıștır. Daha sonra kütle, yay ve sönüm katsayıları gibi sistem parametreleri 
bulunmuştur. Analitik model için sistemin tek serbestlik dereceli eșdeğer modeli kurulmuştur. Laplace yönteminden faydalanılarak başlangıç değerleri altında dinamik cevaplar elde edilmiştir. Ayrıca, serbest titreşim cevaplarını elde etmek için ANSYS programında sonlu eleman benzetim çalışmaları yapılmıştır. Farklı başlangıç yer değiştirme değerleri için deneysel, benzetim ve analitik titreşim cevapları karşılaştırılmıştır. Sonuçların birbiriyle uyumlu olduğu görülmüştür. Sistemlerin eşdeğer modelleri kurularak analitik olarak titreşim cevapları hızlı bir şekilde elde edilebilir. Gelecek çalışmalarda karmaşık geometrili sistemlerin eșdeğer modelleri kurularak titreşim cevaplarının elde edilmesi ve ardından titreşim kontrolünün uygulanması hedeflenmektedir.

\section{Kaynakça}

[1] Sina, S. A., Navazi, H. M., Haddadpour H. 2009. An analytical method for free vibration analysis of functionally graded beams, Materials and Design, Cilt. 30 , s. 741-747.

[2] Giunta, G., Biscani, F., Belouettar, S., Ferreira, A.J.M., Carrera E. 2013. Free vibration analysis of composite beams via refined theories, Composites: Part B, Cilt. 44 , s. 540-552.

[3] Ganesan, R., Zabihollah, A. 2007. Vibration analysis of tapered composite beams using a higherorder finite element. Part I: Formulation, Composite Structures, Cilt. 77, s. 306-318.

[4] Li, J., Hu, X., Li, X. 2016. Free vibration analyses of axially loaded laminated composite beams using a unified higher-order shear deformation theory and dynamic stiffness method. Journal of
Composite Structures, Cilt. 158, s. 308-322.

[5] Vo, T.P., Lee, J. 2009. Flexuraltorsional coupled vibration and buckling of thin-walled open section composite beams using shear-deformable beam theory, International Journal of Mechanical Sciences, Cilt. 51, s. 631-641.

[6] Ghafari, E., Rezaeepazhand, J. 2016. Vibration analysis of rotating composite beams using polynomial based dimensional reduction method. International Journal of Mechanical Sciences, Cilt. 115, s. 93104.

[7] Lee, I., Choi, K.K., Du, L., Gorsich, D. 2008. Dimension reduction method for reliability-based robust design optimization, Computers and Structures, Cilt. 86, s. 1550-1562.

[8] Lu, W., Ge, F., Wu, X., Hong, Y. 2013. Nonlinear dynamics of a submerged floating moored structure by incremental harmonic balance method with FFT. Marine Structures, Cilt. 31, s. 63-81.

[9] Monciet, V. 2015. Combining FFT methods and standard variational principles to compute bounds and estimates for the properties of elastic composites. Computer Methods in Applied Mechanics and Engineering, Cilt. 283, s. 454-473.

[10] Mariot, S., Leroy, V., Pierre, J., Elias, F., Bouthemy, E., Langevin, D. 2015. An FFT approach to the analysis of dynamic properties of gas/liquid interfaces. Colloids and Surfaces A: Physicochemical and Engineering Aspects, Cilt. 473, s. 11-17.

[11] Nagarajaiah, S., Basu, B. 2009. Output only modal identifi cation and structural damage detection using time frequency and wavelet techniques, Earthquake Engineering and Engineering Vibration, Cilt. 8, s.583-605.

[12] Badour, F.A., Sunar, M., Cheeded, L. 2011. Vibration analysis of rotating 
Ş. Yavuz vd. / Eşdeğer Kütle-Yay-Sönüm Elemanı Kullanılan Ankastre Kompozit Bir Kirișin Titreşim Analizi

machinery using time-frequency analysis and wavelet techniques. Journal of Mechanical Systems and Signal Processing, Cilt. 25, s. 20832101.

[13] Haosheng, L., Su, W., Kratz, H. 2007. FFT and wavelet-based analysis of the influence of machine vibrations on hard turned surface topographies. Tshingua Science and Technology, Cilt. 12(4), s. 441-446.

[14] Kabel, M., Merkert, D., Schneider, M. 2015. Use of composite voxels in FFT-based homogenization. Computer Methods in Applied Mechanics and Engineering, Cilt. 294, s. 168-188.

[15] S. Rao , Mechanical Vibrations, 5th ed., Prantice-Hall, Upper Saddle River, 2011.

[16] MicroStrain Inc. 2015. Web adresi: http://www.microstrain.com/wire less/sensors. Erişim tarihi: 02.11.2015.

[17] Kiral, Z., Malgaca L., Akdağ, M. Kiral, B.G. 2009. Experimental Investigation of the Dynamic Response of a Symmetric Laminated Composite Beam Via Laser Vibrometry. Journal of Composite Materials. Cilt, 43(24), s. 2943-2962. 